\title{
The Metabolic Syndrome and Cognitive Decline in the Atherosclerosis Risk in Communities Study (ARIC)
}

\author{
Jennifer L. Dearborn ${ }^{a}$ David Knopman ${ }^{b}$ A. Richey Sharrett ${ }^{c}$ \\ Andrea L.C. Schneider ${ }^{c}$ Clifford R. Jack Jr. ${ }^{d}$ Laura H. Coker ${ }^{\mathrm{e}}$ \\ Alvaro Alonso ${ }^{f}$ Elizabeth Selvin ${ }^{c}$ Thomas H. Mosley ${ }^{g}$ \\ Lynne E. Wagenknecht ${ }^{\mathrm{h}}$ Beverly G. Windham ${ }^{\mathrm{g}}$ Rebecca F. Gottesman ${ }^{\mathrm{a}}$ \\ a Department of Neurology, Johns Hopkins University School of Medicine, Baltimore, Md., \\ ${ }^{b}$ Department of Neurology, Mayo Clinic, Rochester Minn., 'Department of Epidemiology, \\ Johns Hopkins Bloomberg School of Public Health, Baltimore, Md., ${ }^{\mathrm{d}}$ Department of

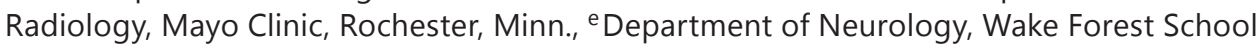 \\ of Medicine, Winston-Salem, N.C., fDivision of Epidemiology and Community \\ Health, School of Public Health, University of Minnesota, Minneapolis, Minn., \\ 9 Division of Geriatrics, Department of Medicine, University of Mississippi School of \\ Medicine, Jackson, Miss., and h'Division of Public Health Sciences, Wake Forest School of \\ Medicine, Winston-Salem, N.C., USA
}

\section{Key Words}

Metabolic syndrome $\cdot$ Cognition $\cdot$ Cognitive decline $\cdot$ Obesity $\cdot$ Hypertension · Dementia

\begin{abstract}
Background: Midlife metabolic syndrome (MetS) may impact cognitive health as a construct independently of hypertension, hyperlipidemia and other components. Methods: 10,866 participants aged 45-64 years at baseline were assessed for MetS and completed cognitive testing at two later time points ( 3 and 9 years from the baseline visit). Results: MetS is associated with increased odds of low cognitive performance in the domains of executive function and word fluency, but not with 6-year cognitive decline. Individual MetS components explained this association (hypertension, diabetes, low HDL, elevated triglycerides and increased waist circumference). Conclusions: A focus on the individual risk factors as opposed to MetS during midlife is important to reduce the incidence of cognitive impairment in later life.
\end{abstract}




\section{Introduction}

Emerging evidence links the metabolic syndrome (MetS) to cognitive decline, but whether the syndrome contributes to worsening cognition beyond the components of the syndrome is less understood [1-3]. Traditional cardiovascular risk factors such as diabetes [4-6], hypertension [7], obesity and smoking have also been associated with an increased risk of dementia $[8,9]$, and as a composite, MetS and vascular risk factors have been shown to be associated with short-term cognitive decline [10-12].

MetS could influence cognition by creating a greater burden of small-vessel disease and subclinical strokes. In addition, individuals with MetS may have a distinct biology that relates to cognitive function through signaling chemokines $[13,14]$. Prior studies demonstrate 'residual risk' of cardiovascular outcomes or dementia in participants with MetS after adjustment for other risk factors $[15,16]$. This study hypothesized that MetS would be associated with a 6-year cognitive decline and that there would be particularly 'high-risk' clusters of MetS components, such as elevated blood pressure, increased waist circumference (WC) and elevated fasting glucose.

\section{Methods}

\section{Study Population}

ARIC (Atherosclerosis Risk in Communities) is a longitudinal, prospective, multisite study, the initial recruitment and study participation of which have previously been described [17]. The study was conducted at four sites (Jackson, Miss., Forsyth County, N.C., Washington County, Md. and suburban Minneapolis, Minn.) and includes a biracial population of adults, who upon initial recruitment at visit 1 were aged 45-64 years. Visit 1 occurred from 1987 to 1989 and visit 5 from 2011 to 2013.

MetS components were evaluated at visit 1 (1987-1989). Neurocognitive testing (see description below) was completed at visit 2 (1990-1992) and visit 4 (1996-1999). Only participants who attended visit 1 , visit 2 and visit 4 were included. Of 11,656 participants who returned for visit 4, participants were additionally excluded for the following reasons: missing cognitive test data $(n=566)$ and adjudicated strokes $(\mathrm{n}=157)$. Because of the small numbers, those who were neither white nor black $(\mathrm{n}=30)$ and the black participants in the Minnesota $(n=12)$ and Washington County cohorts $(n=25)$ were excluded, leaving 10,866 in the analytic population. Participants with missing data on any of the MetS parameters or other covariates were dropped from the analysis specific to the missing parameter. The Institutional Review Boards (IRB) at all institutions approved the study.

\section{Measures}

Cognitive Testing

Three tests were used in the cognitive battery. The Delayed Word Recall (DWR) [18] involves presenting the subject with a list of ten words, and after 5 min asking them to recall the list. This test has been shown to have a high predictive accuracy for Alzheimer's dementia and is primarily a test of verbal learning and recent memory.

The Digit Symbol Substitution Test (DSST) is a test of cognitive processing speed and executive functioning and is a part of the Wechsler Adult Intelligence Scale-Revised (WAIS-R). In this test, a subject is provided with a list of number-symbol pairs, then with a list of numbers and asked to substitute the corresponding symbols. The score (0-93) is determined by translating the correct number of symbols into numbers in $90 \mathrm{~s}$.

In the Word Fluency Test (WFT), participants are asked to produce words beginning with a particular letter and are given $60 \mathrm{~s}$ to complete the task. Three trials were completed with the letters ' $\mathrm{F}$ ', ' $\mathrm{A}$ ' and ' $\mathrm{S}$ ', and proper nouns were excluded. This test assesses expressive language and executive function.

MetS Definition

Five components were used in the definition of MetS assessed at visit 1: elevated blood pressure, increased WC, elevated triglycerides (TGs), low high-density lipoprotein (HDL) and impaired fasting glucose. 
Systolic and diastolic blood pressure was measured in the right arm with the patient in the sitting position, and was recorded as the mean of the last two of three measurements using a random-zero sphygmomanometer. WC was measured in centimeters at the level of the umbilicus. Blood collection methods have been described previously [19-21], and while the majority of participants were fasting during all tests, nonfasting participants were excluded from lipid measurements. TGs were measured by enzymatic methods, and HDL cholesterol was measured after dextran-magnesium precipitation. Serum glucose was measured with the hexokinase/glucose-6-phosphate dehydrogenase method.

MetS was categorized according to the American Heart Association (AHA) [22] criteria. To be categorized as having MetS, the participants had at least three of the following five criteria: (1) elevated WC: WC $>102 \mathrm{~cm}$ in men or $>88 \mathrm{~cm}$ in women; (2) low HDL: HDL $<40 \mathrm{mg} / \mathrm{dl}$ in men or $<50 \mathrm{mg} / \mathrm{dl}$ in women; (3) elevated blood pressure: $\geq 130 \mathrm{~mm}$ Hg systolic or $\geq 85 \mathrm{~mm} \mathrm{Hg}$ diastolic or on medication for hypertension; (4) elevated TGs: $\geq 150 \mathrm{mg} / \mathrm{dl}$, and (5) impaired fasting glucose or diabetes: elevated fasting glucose $\geq 100$ $\mathrm{mg} / \mathrm{dl}$, elevated nonfasting glucose $\geq 200 \mathrm{mg} / \mathrm{dl}$ or on medication for diabetes. Separate variables were created for MetS (yes/no) and the number of MetS components.

Covariates

A combined variable of race and field center (race-center) was created to account for confounding by study design, for which there are five indicators (Maryland whites, Minnesota whites, North Carolina whites, North Carolina blacks and Mississippi blacks). Diabetes was defined by the current use of diabetes medication, a fasting glucose of $\geq 126 \mathrm{mg} / \mathrm{dl}$ or a nonfasting glucose of $\geq 200 \mathrm{mg} / \mathrm{dl}$. Covariates in adjusted models included age, race-center, education, tobacco use, alcohol and history of coronary heart disease. Participants also brought current medications to each visit, which were recorded by trained personnel. Participants categorized with coronary heart disease included those with a history of myocardial infarction, myocardial infarction determined by ECG adjudication, or history of coronary artery bypass graft or angioplasty.

\section{Statistical Methods}

Baseline characteristics for participants were analyzed for each variable. Between-group comparisons were made stratifying for MetS, sex and race. Test scores at visits 2 and 4, and the difference between these two, were each main dependent variables in separate models, and were analyzed as both continuous and categorical variables. All analyses were performed using Stata version 12 (StataCorp, College Station, Tex., USA). A two-sided $p$ value of $<0.05$ was considered significant for all analyses.

Cross-Sectional Analysis

Logistic regression was used to examine performance in the lowest quintile at each visit compared with quintiles 2-5, with cumulative MetS components, presence of MetS, or individual MetS components as predictors in separate models. Interaction terms were evaluated between pairs of components, such as WC and elevated blood pressure, and were not included in final models.

A MetS cluster refers to groupings of 3-5 MetS components. A separate linear regression model defined cognitive performance for each test (3 models total), with MetS components as predictors. A predicted test score for each cluster was created using a dummy variable for each MetS characteristic indicating its presence or absence for a 'typical subject', and the resulted score was computed. Predicted scores were compared across MetS clusters.

\section{Longitudinal Association}

The difference in test scores between visit 4 and visit 2 was calculated by subtracting the visit 4 score from the visit 2 score, with a positive number indicating a decline in test scores. The date at visit 2 was subtracted from the date at visit 4 , and the score difference was divided by the date difference to obtain the mean decline per year. Because not all participants were tested exactly 6 years apart, to standardize years of cognitive decline, this number was multiplied by 6. A linear regression model was created, with MetS components as predictors, adjusting for the covariates described above. Interaction was examined as detailed for logistic regression models. 
Risk in Communities Study (ARIC)

Table 1. Baseline participant characteristics and cognitive test scores at visit 2 by sex and MetS status

\begin{tabular}{|c|c|c|c|c|c|}
\hline & \multirow[t]{2}{*}{ Sample size, $n$} & \multicolumn{2}{|l|}{ Women } & \multicolumn{2}{|l|}{ Men } \\
\hline & & no MetS & MetS & no MetS & MetS \\
\hline Age, years & 10,500 & $52.9 \pm 5.6$ & $54.8 \pm 5.5$ & $54.1 \pm 5.7$ & $54.7 \pm 5.6$ \\
\hline Education & 10,487 & & & & \\
\hline Less than high school & & $508(13.3)$ & $432(25.7)$ & 491 (17.3) & $297(16.9)$ \\
\hline High school to college & & $1,787(46.7)$ & $1,006(48.6)$ & $1,023(36.1)$ & $728(41.5)$ \\
\hline Postgraduate training & & $1,533(40.0)$ & $532(25.7)$ & $1,322(46.6)$ & $728(41.5)$ \\
\hline Race & 10,500 & & & & \\
\hline Black & & $711(18.6)$ & $579(28.0)$ & 447 (15.8) & $226(12.9)$ \\
\hline White & & $3,121(81.5)$ & $1,492(72.0)$ & $2,391(84.3)$ & $1,533(87.2)$ \\
\hline Smoking & 10,493 & & & & \\
\hline Current or former & & $1,735(45.3)$ & $871(42.1)$ & $1,887(66.5)$ & $1,269(72.2)$ \\
\hline Never & & $2,092(54.7)$ & 1,199 (57.9) & $951(33.5)$ & $489(27.8)$ \\
\hline Alcohol & 10,462 & & & & \\
\hline Current or former & & $2,722(71.3)$ & $1,250(60.6)$ & $2,454(86.8)$ & $1,544(88.1)$ \\
\hline Never & & 1,097 (28.7) & $813(39.4)$ & $374(13.2)$ & 208 (11.9) \\
\hline Body mass index & 10,495 & $25.4 \pm 4.8$ & $31.0 \pm 5.8$ & $26.1 \pm 3.3$ & $29.7 \pm 4.0$ \\
\hline Symptomatic heart disease & 10,441 & $188(5.0)$ & $172(8.4)$ & $175(6.2)$ & $176(10.1)$ \\
\hline \multicolumn{6}{|l|}{ MetS characteristics } \\
\hline $\mathrm{WC}, \mathrm{cm}$ & 10,496 & $88.5 \pm 12.7$ & $104.4 \pm 13.6$ & $95.2 \pm 8.9$ & $105.2 \pm 9.8$ \\
\hline Systolic blood pressure, $\mathrm{mm} \mathrm{Hg}$ & 10,497 & $113.6 \pm 15.7$ & $126.7 \pm 18.0$ & $116.8 \pm 14.7$ & $126.1 \pm 16.3$ \\
\hline Diastolic blood pressure, $\mathrm{mm} \mathrm{Hg}$ & 10,496 & $69.6 \pm 9.9$ & $75.2 \pm 10.2$ & $72.9 \pm 9.7$ & $77.5 \pm 10.5$ \\
\hline TGs, mg/dl & 10,500 & $97.3 \pm 44.2$ & $168.1 \pm 97.3$ & $106.2 \pm 53.1$ & $194.7 \pm 115.0$ \\
\hline $\mathrm{HDL}, \mathrm{mg} / \mathrm{dl}$ & 10,500 & $64.1 \pm 16.1$ & $48.0 \pm 13.6$ & $48.3 \pm 12.7$ & $36.9 \pm 9.6$ \\
\hline Fasting glucose, $\mathrm{mg} / \mathrm{dl}$ & 10,500 & $95.2 \pm 14.9$ & $116.0 \pm 41.2$ & $99.8 \pm 15.9$ & $115.6 \pm 32.5$ \\
\hline Diabetes & 10,496 & $66(1.7)$ & 395 (19.1) & $102(3.6)$ & $289(16.4)$ \\
\hline On lipid medication & 10,426 & $15(0.4)$ & $140(6.8)$ & $32(1.1)$ & $105(6.0)$ \\
\hline On antihypertensive medication & 10,447 & $401(10.5)$ & $948(46.0)$ & $298(10.6)$ & $636(36.3)$ \\
\hline \multicolumn{6}{|l|}{ Cognitive test scores } \\
\hline DWR & 10,478 & $7.1 \pm 1.4$ & $6.8 \pm 1.4$ & $6.5 \pm 1.5$ & $6.3 \pm 1.4$ \\
\hline DSST & 10,478 & $50.4 \pm 12.9$ & $45.0 \pm 14.1$ & $44.5 \pm 12.7$ & $43.9 \pm 11.9$ \\
\hline WFT & 10,476 & $36.1 \pm 11.9$ & $32.5 \pm 11.5$ & $33.8 \pm 12.5$ & $33.0 \pm 12.0$ \\
\hline
\end{tabular}

Values represent mean \pm SD or $\mathrm{n}(\%)$ unless otherwise specified.

\section{Results}

\section{Participants}

Of the 10,866 participants included in the study, $56.2 \%(n=6,109)$ were women and $36.5 \%(\mathrm{n}=3,830)$ had MetS at baseline (table 1). Based on WC measurements, $50.3 \%(\mathrm{n}=$ 5,497 ) participants were classified as obese. Body mass index, WC and other parameters of MetS (elevated blood pressure, blood glucose and TGs) were considerably increased in participants that met the criteria for MetS by design. HDL, which is protective against vascular disease if elevated, was also significantly lower in the MetS participants. The percentage of participants with each MetS component is shown in online supplementary eTable 1 (for all online suppl. material, see www.karger.com/doi/10.1159/000362265).

\section{Cross-Sectional Association}

The relationships of visit 1 MetS components and MetS to low cognitive performance at visits 2 and 4 are shown in table 2. MetS was associated with increased odds of poor test performance for three tests across all visits (with the exception of DSST at visit 2). Comparing visit 4 to visit 2, more MetS components were associated with poor test performance on DWR 

Dearborn et al.: The Metabolic Syndrome and Cognitive Decline in the Atherosclerosis
Risk in Communities Study (ARIC)

Table 2. MetS components and odds of performance in the lowest test quintile by visit

\begin{tabular}{|c|c|c|c|c|c|c|}
\hline & \multicolumn{2}{|c|}{ DWR, OR (95\% CI) } & \multicolumn{2}{|c|}{ DSST, OR (95\% CI) } & \multicolumn{2}{|c|}{ WFT, OR (95\% CI) } \\
\hline & visit 2 & visit 4 & visit 2 & visit 4 & visit 2 & visit 4 \\
\hline Increased WC & $\begin{array}{l}1.11 \\
(1.00,1.24)\end{array}$ & $\begin{array}{l}1.15 \\
(1.04,1.27)\end{array}$ & $\begin{array}{l}1.22 \\
(1.07,1.40)\end{array}$ & $\begin{array}{l}1.31 \\
(1.15,1.49)\end{array}$ & $\begin{array}{l}1.24 \\
(1.11,1.39)\end{array}$ & $\begin{array}{l}1.19 \\
(1.07,1.33)\end{array}$ \\
\hline Elevated blood pressure & $\begin{array}{l}1.07 \\
(0.96,1.19)\end{array}$ & $\begin{array}{l}1.06 \\
(0.96,1.17)\end{array}$ & $\begin{array}{l}1.10 \\
(0.96,1.25)\end{array}$ & $\begin{array}{l}1.22 \\
(1.08,1.39)\end{array}$ & $\begin{array}{l}1.16 \\
(1.04,1.30)\end{array}$ & $\begin{array}{l}1.10 \\
(0.99,1.23)\end{array}$ \\
\hline Elevated TGs & $\begin{array}{l}1.09 \\
(0.98,1.24)\end{array}$ & $\begin{array}{l}1.18 \\
(1.06,1.32)\end{array}$ & $\begin{array}{l}1.03 \\
(0.90,1.19)\end{array}$ & $\begin{array}{l}1.21 \\
(1.05,1.40)\end{array}$ & $\begin{array}{l}1.15 \\
(1.02,1.29)\end{array}$ & $\begin{array}{l}1.11 \\
(0.98,1.25)\end{array}$ \\
\hline Low HDL & $\begin{array}{l}1.09 \\
(0.98,1.22)\end{array}$ & $\begin{array}{l}1.19 \\
(1.08,1.32)\end{array}$ & $\begin{array}{l}1.10 \\
(0.96,1.26)\end{array}$ & $\begin{array}{l}1.15 \\
(1.00,1.31)\end{array}$ & $\begin{array}{l}1.1 \\
(0.99,1.23)\end{array}$ & $\begin{array}{l}1.11 \\
(1.00,1.24)\end{array}$ \\
\hline $\begin{array}{l}\text { Elevated fasting glucose or } \\
\text { diabetes }\end{array}$ & $\begin{array}{l}1.02 \\
(0.92,1.14)\end{array}$ & $\begin{array}{l}1.00 \\
(0.91,1.11)\end{array}$ & $\begin{array}{l}1.14 \\
(1.00,1.29)\end{array}$ & $\begin{array}{l}1.17 \\
(1.03,1.33)\end{array}$ & $\begin{array}{l}1.06 \\
(0.95,1.18)\end{array}$ & $\begin{array}{l}1.08 \\
(0.97,1.20)\end{array}$ \\
\hline MetS & $\begin{array}{l}1.12 \\
(1.01,1.15)\end{array}$ & $\begin{array}{l}1.13 \\
(1.02,1.25)\end{array}$ & $\begin{array}{l}1.11 \\
(0.98,1.26)\end{array}$ & $\begin{array}{l}1.24 \\
(1.09,1.41)\end{array}$ & $\begin{array}{l}1.25 \\
(1.12,1.40)\end{array}$ & $\begin{array}{l}1.18 \\
(1.06,1.32)\end{array}$ \\
\hline
\end{tabular}

Each component of the MetS is shown in a separate model for visits 2 and 4; all are adjusted for age, race-center number, education, sex, coronary artery disease, smoking and drinking status. Results for composite MetS are shown in a separate model with the same covariates. $\mathrm{OR}=$ Odds ratio.

Table 3. MetS components and 6-year change in test scores by sex between visits 2 and 4

\begin{tabular}{|c|c|c|c|c|c|c|}
\hline & \multicolumn{2}{|c|}{ DWR, $\beta(95 \%$ CI) } & \multicolumn{2}{|c|}{ DSST, $\beta(95 \%$ CI $)$} & \multicolumn{2}{|c|}{ WFT, $\beta(95 \%$ CI $)$} \\
\hline & men & women & men & women & men & women \\
\hline Increased WC & $\begin{array}{l}0.03 \\
(-0.06,0.12)\end{array}$ & $\begin{array}{l}0.05 \\
(-0.03,0.15)\end{array}$ & $\begin{array}{l}-0.02 \\
(-0.39,0.35)\end{array}$ & $\begin{array}{l}0.28 \\
(-0.11,0.67)\end{array}$ & $\begin{array}{l}0.34 \\
(-0.13,0.82)\end{array}$ & $\begin{array}{l}-0.28 \\
(-0.71,0.14)\end{array}$ \\
\hline Elevated blood pressure & $\begin{array}{l}-0.05 \\
(-0.14,0.48)\end{array}$ & $\begin{array}{l}-0.01 \\
(-0.09,0.08)\end{array}$ & $\begin{array}{l}0.39 \\
(0.01,0.76)\end{array}$ & $\begin{array}{l}0.05 \\
(-0.36,0.45)\end{array}$ & $\begin{array}{l}0.11 \\
(-0.37,0.60)\end{array}$ & $\begin{array}{l}0.41 \\
(-0.03,0.85)\end{array}$ \\
\hline Elevated TGs & $\begin{array}{l}0.01 \\
(-0.09,0.11)\end{array}$ & $\begin{array}{l}0.10 \\
(0.01,0.20)\end{array}$ & $\begin{array}{l}0.01 \\
(-0.38,0.39)\end{array}$ & $\begin{array}{l}0.58 \\
(0.13,1.03)\end{array}$ & $\begin{array}{l}0.23 \\
(-0.26,0.73)\end{array}$ & $\begin{array}{l}-0.15 \\
(-0.64,0.34)\end{array}$ \\
\hline Low HDL & $\begin{array}{l}-0.02 \\
(-0.11,0.07)\end{array}$ & $\begin{array}{l}0.05 \\
(-0.04,0.13)\end{array}$ & $\begin{array}{l}0.14 \\
(-0.23,0.51)\end{array}$ & $\begin{array}{l}0.24 \\
(-0.16,0.63)\end{array}$ & $\begin{array}{l}0.77 \\
(0.29,1.24)\end{array}$ & $\begin{array}{l}0.30 \\
(-0.73,0.13)\end{array}$ \\
\hline $\begin{array}{l}\text { Elevated fasting glucose or } \\
\text { diabetes }\end{array}$ & $\begin{array}{l}0.03 \\
(-0.06,0.12)\end{array}$ & $\begin{array}{l}0.01 \\
(-0.07,0.09)\end{array}$ & $\begin{array}{l}0.22 \\
(-0.15,0.58)\end{array}$ & $\begin{array}{l}-0.13 \\
(-0.51,0.26)\end{array}$ & $\begin{array}{l}0.21 \\
(-0.26,0.68)\end{array}$ & $\begin{array}{l}-0.15 \\
(-0.57,0.27)\end{array}$ \\
\hline Diabetes & $\begin{array}{l}0.14 \\
(-0.01,0.30)\end{array}$ & $\begin{array}{l}0.16 \\
(0.01,0.30)\end{array}$ & $\begin{array}{l}1.04 \\
(0.42,1.67)\end{array}$ & $\begin{array}{l}0.71 \\
(0.04,1.39)\end{array}$ & $\begin{array}{l}0.81 \\
(0.001,1.61)\end{array}$ & $\begin{array}{l}1.21 \\
(0.47,1.95)\end{array}$ \\
\hline MetS & $\begin{array}{l}0.01 \\
(-0.08,0.11)\end{array}$ & $\begin{array}{l}0.05 \\
(-0.04,0.14)\end{array}$ & $\begin{array}{l}0.20 \\
(-0.17,0.58)\end{array}$ & $\begin{array}{l}0.10 \\
(-0.31,0.50)\end{array}$ & $\begin{array}{l}0.44 \\
(-0.04,0.92)\end{array}$ & $\begin{array}{l}-0.28 \\
(-0.72,0.16)\end{array}$ \\
\hline
\end{tabular}

Positive values indicate a decline in cognitive test score. Results for MetS are shown in a separate model. DWR has a range from 0 to 10 , DSST from 0 to 92 and WFT from 0 to 88 .

and DSST at visit 4, while a similar number of MetS components were associated with WFT at visits 2 and 4. Overall, the relationships observed were the strongest for the DSST and were more consistent for visit 4 cognitive data than for visit 2 data.

All MetS components were significantly associated with increased odds of performing in the lowest quintile on the DSST for visit 4, but only increased WC and elevated glucose achieved statistical significance at visit 2. For DSST at visit 4, increased WC and elevated blood pressure had the strongest associations, with a low HDL reaching marginal statistical significance. WC was the only variable that maintained significance across all three tests. 
Dearborn et al:: The Metabolic Syndrome and Cognitive Decline in the Atherosclerosis Risk in Communities Study (ARIC)

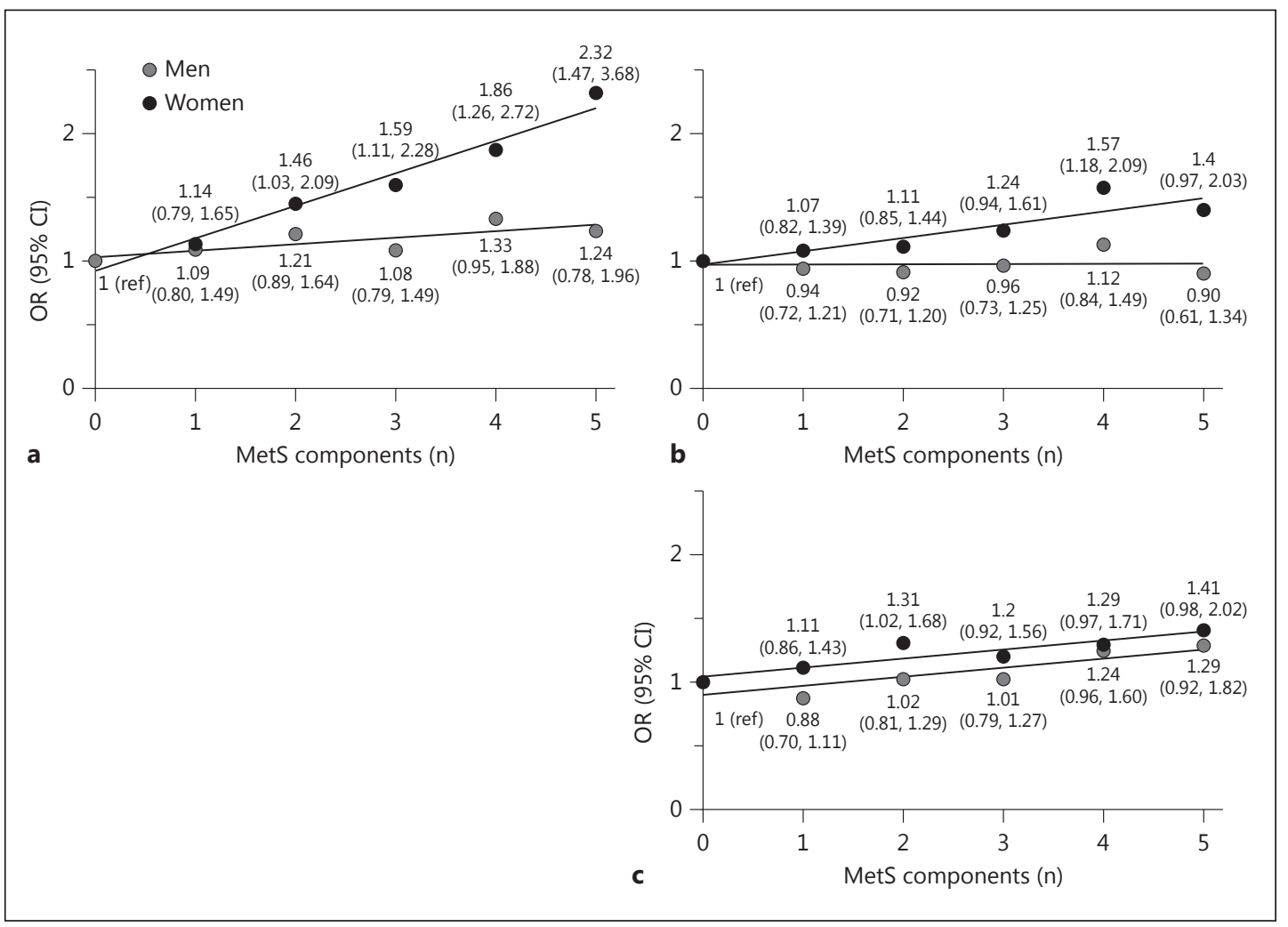

Fig. 1. Number of MetS components (elevated blood pressure, elevated fasting glucose, increased WC, increased TGs and low HDL) at baseline and adjusted odds ratio (OR) of the lowest test quintile performance at visit 4 with $95 \%$ CI. Covariates include age, education, race-center number, sex, smoking and drinking status; the reference (ref) category was zero MetS components. a DSST. b WFT. c DWR.

An increasing number of MetS components were associated with increased odds of performance in the lowest quintile for women only. Again, these results were stronger for the DSST, where having five components versus no components was associated with increased odds of performance in the lowest test quintile (fig. 1). Interaction terms for MetS components and gender were significant in DSST and WFT, but not DWR [adjusted odds ratio MetS - gender $(95 \%$ CI)]: DWR $1.00(0.93,1.07)$, DSST $1.13(1.03,1.23)$ and WFT $1.1(1.02$, 1.18).

MetS clusters, in the multivariable model of MetS components as predictors of the performance on the DSST, were not significantly different from each other (fig. 2). Having no MetS components trended toward higher test scores at visit 4 than having all five components. When MetS was included in the model with all of the individual components, it did not reach statistical significance for worse cognitive performance, indicating that MetS did not contribute to worse cognitive function above and beyond the individual factors [MetS adjusted $\beta$ (95\% CI) DWR: $-0.04(-0.15,0.07)$, DSST $-0.10(-0.81,0.62)$ and WFT $-0.21(-1.03,0.61)]$.

\section{Longitudinal Association}

MetS was not a significant predictor of the 6-year change in the test score (table 3). Diabetes was the only component associated with decline on all three tests; however, in the participants, impaired fasting glucose (greater than $100 \mathrm{mg} / \mathrm{dl}$ ) or diabetes was not associated with cognitive decline. In men, elevated blood pressure (DSST), elevated TGs (DWR) 


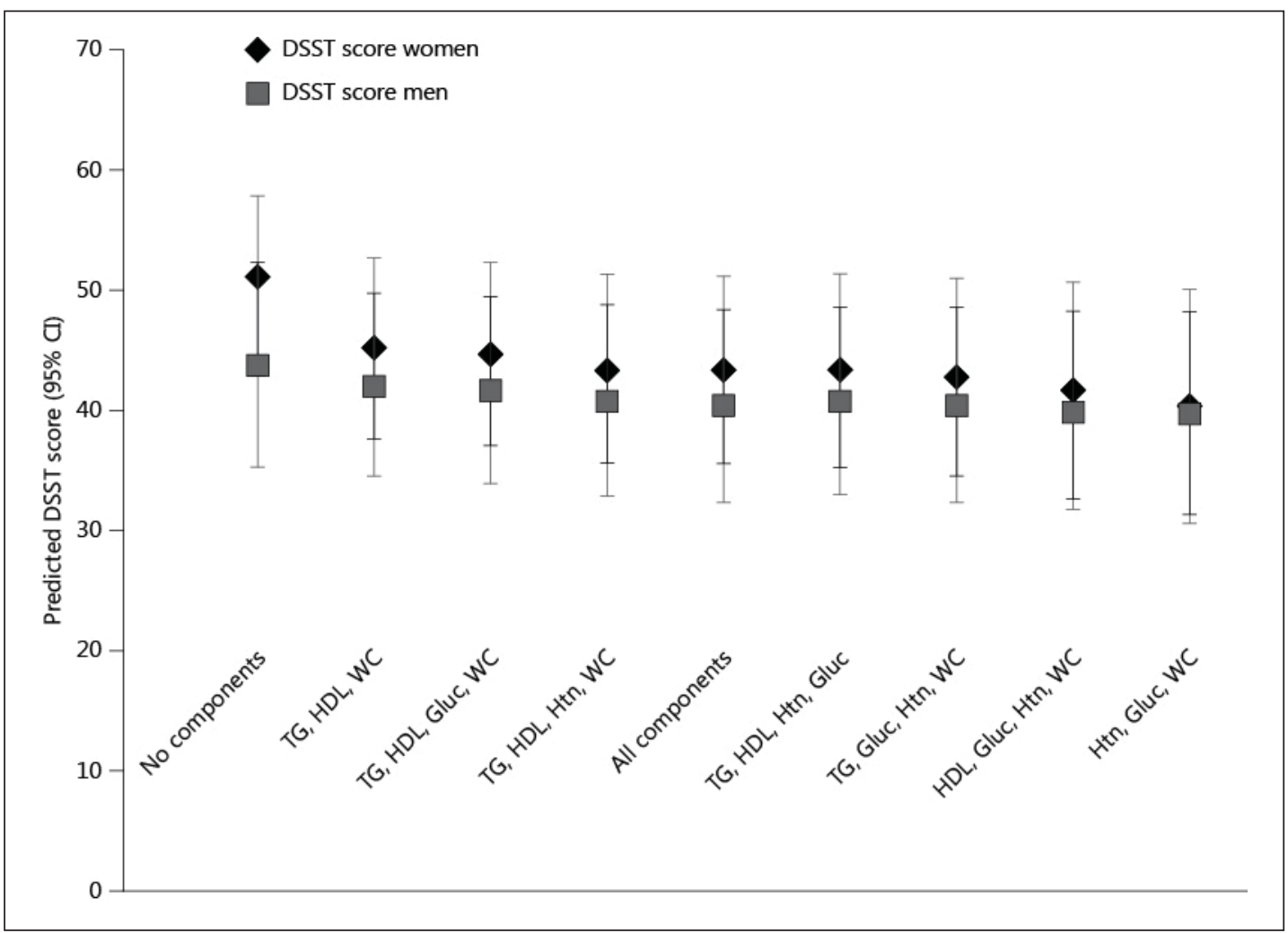

Fig. 2. Predicted mean DSST score for the 'average' participant with each MetS cluster. Scores are shown for men and women with error bars for standard deviation. The model is adjusted for age, education, race-center number, smoking and drinking status. TG = Elevated TGs; HDL = low HDL; WC = elevated WC; Gluc = impaired fasting glucose; Htn = elevated blood pressure.

and low HDL (WFT) were associated with cognitive decline in the respective cognitive tests, but WC carried no association with more decline. In women, elevated TGs (DWR) and diabetes (DWR, DSST and WFT) were associated with cognitive decline. When stratified by race, if diabetes was associated with test score decline in white participants only, interaction terms for diabetes and race were not significant (online suppl. eTable 2).

\section{Discussion}

This prospective study found that the presence of MetS at baseline was associated with worse cognitive performance on three tests at individual visits in later life. The contribution of MetS to poor performance was not above and beyond the contribution made by individual vascular risk factors. This result was robust for the DSST, which is a test of processing speed and executive function, as well as for the WFT, which measures language and executive function.

The decrement in function in the DSST and the WFT was more concordant with changes in function related to subcortical white matter disease or vascular cognitive impairment as opposed to Alzheimer's disease pathology. Lacunar infarcts, which are a marker of cerebral small vessel disease, have been linked to decreased performance on the DSST [23], most likely because subcortical disease increases task-processing time. Risk factors such as obesity and 
hypertension are associated with psychomotor slowing and executive function deficits [24]. The relationship between low performance on the DWR and MetS was the weakest, as this test is preferentially affected in Alzheimer's disease [18].

These findings are consistent with other large studies, which have shown that traditional vascular risk factors are associated with dementia $[8,15,25]$. One study [25] suggested that a composite score of four cardiovascular risk factors (hypertension, hyperlipidemia, smoking and diabetes) at midlife was associated with a greater risk of dementia in later life in a dosedependent fashion. Similarly, the clustering of midlife obesity, hypertension and elevated cholesterol was shown to be an additive in the risk of dementia [8].

Our results emphasize that MetS is no more than a risk profile of individual risk factors with respect to its impact on cognition. The MetS definition does not include risk factors that are known to impact cognition, such as smoking. WC seemed to be a particularly robust predictor of the worst cognitive performance at visit 4. One possible explanation is that WC was the most prevalent MetS characteristic (online suppl. eTable 1) and may be an early indicator of poor cardiovascular health, even before other risk factors develop.

The change in cognitive performance, compared with performance on tests administered at one point in time, has less potential for confounding, particularly for factors that are stable within individuals, such as their education or early experiences. However, the cumulative MetS or the number of components was not associated with a 6-year cognitive decline in this age group with the exception of diabetes (table 3). Of note, the effect sizes observed are small and may not be clinically significant at the time studied. As this study only measures the 6-year decline, those with some decline may be more likely to progress to dementia. ARIC investigators have previously shown that both diabetes and elevated blood pressure are associated with cognitive decline [11]. The risk of cardiovascular disease contributed by MetS in ARIC was not in excess of the level explained by the individual components [26], and the present study suggests that the same pattern holds for cognitive decline.

An important study of the contribution of midlife vascular risk factors to cognitive health at older ages was the Honolulu-Asia Aging Study, which included middle-age Japanese men in longitudinal follow-up over 40 years. This cohort followed participants to a diagnosis of dementia in their elderly years and found that higher MetS z-scores were associated with a higher likelihood of vascular dementia [15]. The present analysis adds to this literature by examining midlife risk factors to describe cognitive function even before the onset of clinical dementia or mild cognitive impairment.

The AHA has termed cardiovascular health as including 7 potentially modifiable risk factors that contribute to cardiovascular morbidity [27] and has set goal levels for middleaged adults. A recent study suggested that a greater number of these ideal cardiovascular metrics were associated with better cognitive function [28]. As opposed to MetS, the 7 risk factors may be a better way to think about health, so that the emphasis for public health messages can be that changing each factor individually reduces morbidity.

Another important result of this study is that women with more MetS components have increased odds of performing in the lowest quintile for the DSST and the WFT, as compared with men. MetS and insulin resistance have been associated with poorer executive cognitive function in middle-age women but not in men [29], and other studies demonstrated that MetS increases the risk of cardiovascular disease in women more than in men [26, 30]. Taken together, this literature suggests that a sex difference exists in the influence of vascular risk factors on the cerebrovascular burden of disease and brain health. This is in contradiction to other findings that more MetS components were associated with worse cognitive outcomes, and obesity was a risk factor for lower cognitive functioning in men only [31-33]. More work is needed to explore sex-specific outcomes in cognitive decline. 
The strengths of the analysis are the size and the larger percentage of blacks in the population. The change in cognition was used as an outcome measure, which is more robust to potential confounding than cognitive measures obtained at one visit. Our failure to find associations with cognitive change in participants may reflect that participants are relatively young at study onset, and less likely to have developed mild-cognitive impairment or dementia. The cognitive measures used are more robust than chart reviews or the Mini-Mental State Examination, which do not delineate cognitive domains of impairment.

The study limitations include the possibility of unmeasured confounders to this relationship, such as the presence of obesity in childhood or young adulthood, and early-life cognitive measures, such as intelligence quotient. This study by design looked at the contribution of midlife MetS on later cognitive change and did not include those that developed MetS components after visit 1 . This may underestimate the effect size seen with cognitive change and reflects the most conservative estimate of the results. In addition, the participants do not include those lost to attrition in ARIC, and therefore may reflect a selection bias. It may be that the 'unhealthiest' are the participants who did not return to follow-up visits, and therefore our population may not include those who are most likely to have cognitive decline, again underestimating the effect size.

In this cohort of young-elderly participants, the number of MetS components was associated with increased odds of poor cognitive performance on tests of executive and language function. MetS was not associated with a 6-year cognitive change. The individual components, such as WC, elevated blood pressure and diabetes, explained the poor cognitive function observed. Our results support efforts by AHA and other groups, to target markers of cardiovascular health, rather than grouping heterogeneous risk factors (such as in MetS), which may not add information above and beyond the individual components. Future directions should focus on defining accurate biomarkers of cardiovascular health in relationship to cognition so that health behaviors can be linked to pathophysiology. This will further clarify midlife vulnerabilities to dementia so that efforts can be focused on treatment and intervention before disease onset.

\section{Acknowledgements}

The ARIC study is carried out as a collaborative. It is supported by the following National Heart, Lung, and Blood Institute contracts (HHSN268201100005C, HHSN268201100006C, HHSN268201100007C, HHSN268201100008C, HHSN268201100009C, HHSN268201100010C, HHSN268201100011C and HHSN268201100012C). The authors thank the staff and the participants of the ARIC study for their important contributions.

\section{References}

$>1$ McEvoy LK, Laughlin GA, Barrett-Connor E, et al: Metabolic syndrome and 16-year cognitive decline in community-dwelling older adults. Ann Epidemiol 2012;22:310-317.

-2 Yates KF, Sweat V, Yau PL, Turchiano MM, Convit A: Impact of metabolic syndrome on cognition and brain: a selected review of the literature. Arterioscler Thromb Vasc Biol 2012;32:2060-2067.

3 Muller M, Tang MX, Schupf N, Manly JJ, Mayeux R, Luchsinger JA: Metabolic syndrome and dementia risk in a multiethnic elderly cohort. Dement Geriatr Cogn Disord 2007;24:185-192.

$\checkmark 4$ Christman AL, Matsushita K, Gottesman RF, et al: Glycated haemoglobin and cognitive decline: the Atherosclerosis Risk in Communities (ARIC) study. Diabetologia 2011;54:1645-1652.

5 Cukierman T, Gerstein HC, Williamson JD: Cognitive decline and dementia in diabetes - systematic overview of prospective observational studies. Diabetologia 2005;48:2460-2469.

6 Biessels GJ, Staekenborg S, Brunner E, Brayne C, Scheltens P: Risk of dementia in diabetes mellitus: a systematic review. Lancet Neurol 2006;5:64-74. 
Dearborn et al.: The Metabolic Syndrome and Cognitive Decline in the Atherosclerosis Risk in Communities Study (ARIC)

7 Knopman DS, Mosley TH, Catellier DJ, Coker LH; Atherosclerosis Risk in Communities Study Brain MRI Study: Fourteen-year longitudinal study of vascular risk factors, APOE genotype, and cognition: the ARIC MRI Study. Alzheimers Dement 2009;5:207-214.

-8 Kivipelto M, Ngandu T, Fratiglioni L, et al: Obesity and vascular risk factors at midlife and the risk of dementia and Alzheimer disease. Arch Neurol 2005;62:1556-1560.

$>9$ Rockwood K, Ebly E, Hachinski V, Hogan D: Presence and treatment of vascular risk factors in patients with vascular cognitive impairment. Arch Neurol 1997;54:33-39.

10 Yaffe K, Kanaya A, Lindquist K, et al: The metabolic syndrome, inflammation, and risk of cognitive decline. JAMA 2004;292:2237-2242.

11 Knopman D, Boland LL, Mosley T, et al: Cardiovascular risk factors and cognitive decline in middle-aged adults. Neurology 2001;56:42-48.

12 Raffaitin C, Feart C, Le Goff M, et al: Metabolic syndrome and cognitive decline in French elders: the Three-City Study. Neurology 2011;76:518-525.

13 Hutley L, Prins JB: Fat as an endocrine organ: relationship to the metabolic syndrome. Am J Med Sci 2005;330: 280-289.

14 Lieb W, Beiser AS, Vasan RS, et al: Association of plasma leptin levels with incident Alzheimer disease and MRI measures of brain aging. JAMA 2009;302:2565-2572.

15 Kalmijn S, Foley D, White L, et al: Metabolic cardiovascular syndrome and risk of dementia in JapaneseAmerican elderly men. The Honolulu-Asia aging study. Arterioscler Thromb Vasc Biol 2000;20:2255-2260.

16 Gami AS, Witt BJ, Howard DE, et al: Metabolic syndrome and risk of incident cardiovascular events and death: a systematic review and meta-analysis of longitudinal studies. J Am Coll Cardiol 2007;49:403-414.

$\checkmark 17$ The Atherosclerosis Risk in Communities (ARIC) Study: design and objectives. The ARIC investigators. Am J Epidemiol 1989;129:687-702.

18 Knopman DS, Ryberg S: A verbal memory test with high predictive accuracy for dementia of the Alzheimer type. Arch Neurol 1989;46:141-145.

19 Warnick GR, Benderson J, Albers JJ: Dextran sulfate- $\mathrm{Mg}^{2+}$ precipitation procedure for quantitation of highdensity-lipoprotein cholesterol. Clin Chem 1982;28:1379-1388.

20 Nagele U, Hagele EO, Sauer G, et al: Reagent for the enzymatic determination of serum total triglycerides with improved lipolytic efficiency. J Clin Chem Clin Biochem 1984;22:165-174.

21 Papp AC, Hatzakis H, Bracey A, Wu KK: ARIC hemostasis study - I. Development of a blood collection and processing system suitable for multicenter hemostatic studies. Thromb Haemost 1989;61:15-19.

-22 Grundy SM, Cleeman JI, Daniels SR, et al: Diagnosis and management of the metabolic syndrome: an American Heart Association/National Heart, Lung, and Blood Institute Scientific Statement. Circulation 2005;112: 2735-2752.

23 van de Pol LA, Korf ES, van der Flier WM, et al: Magnetic resonance imaging predictors of cognition in mild cognitive impairment. Arch Neurol 2007;64:1023-1028.

24 Wolf PA, Beiser A, Elias MF, Au R, Vasan RS, Seshadri S: Relation of obesity to cognitive function: importance of central obesity and synergistic influence of concomitant hypertension. The Framingham Heart Study. Curr Alzheimer Res 2007;4:111-116.

25 Whitmer RA, Sidney S, Selby J, Johnston SC, Yaffe K: Midlife cardiovascular risk factors and risk of dementia in late life. Neurology 2005;64:277-281.

-26 McNeill AM, Rosamond WD, Girman CJ, et al: The metabolic syndrome and 11-year risk of incident cardiovascular disease in the atherosclerosis risk in communities study. Diabetes Care 2005;28:385-390.

27 Folsom AR, Yatsuya H, Nettleton JA, et al: Community prevalence of ideal cardiovascular health, by the American Heart Association definition, and relationship with cardiovascular disease incidence. J Am Coll Cardiol 2011;57:1690-1696.

28 Reis JP, Loria CM, Launer LJ, et al: Cardiovascular health through young adulthood and cognitive functioning in midlife. Ann Neurol 2013;73:170-179.

29 Schuur M, Henneman P, van Swieten JC, et al: Insulin-resistance and metabolic syndrome are related to executive function in women in a large family-based study. Eur J Epidemiol 2010;25:561-568.

30 Pischon T, Hu FB, Rexrode KM, Girman CJ, Manson JE, Rimm EB: Inflammation, the metabolic syndrome, and risk of coronary heart disease in women and men. Atherosclerosis 2008;197:392-399.

-31 Elias MF, Elias PK, Sullivan LM, Wolf PA, D’Agostino RB: Lower cognitive function in the presence of obesity and hypertension: the Framingham heart study. Int J Obes Relat Metab Disord 2003;27:260-268.

32 Elias MF, Elias PK, Sullivan LM, Wolf PA, D’Agostino RB: Obesity, diabetes and cognitive deficit: the Framingham Heart Study. Neurobiol Aging 2005;26(suppl 1):11-16.

-33 Cavalieri M, Ropele S, Petrovic K, et al: Metabolic syndrome, brain magnetic resonance imaging, and cognition. Diabetes Care 2010;33:2489-2495. 